\title{
Attitudes of Palestinian Dentists toward Restoration of Endodontically Treated Teeth
}

\section{Tarek H Rabi}

\begin{abstract}
Endodontically treated tooth might weaken after procedure. To reinforce it, various methods are employed. This study was carried out to evaluate the attitude of Palestinian dentists toward the restoration of such teeth. Three hundred randomly chosen dentists were given an online questionnaire consisted of 18 questions. Results were deduced by Chi-square test with $p$-values as supplements. A total of $78.4 \%$ respondents believed that there is no need of the post as reinforcement. A total of $55.9 \%$ believed that it reinforces the tooth and decrease chances of fracture. Ferrule and prefabricated posts with core build-up were also preferred for restoration.
\end{abstract}

Keywords: Core build-up, Post and core, Restoration of endodontically treated teeth, Root canal treatment.

How to cite this article: Rabi TH. Attitudes of Palestinian Dentists toward Restoration of Endodontically Treated Teeth. Int J Prosthodont Restor Dent 2015;5(2):44-50

Source of support: Nil

Conflict of interest: None

\section{INTRODUCTION}

Endodontic therapy mainly aims to help maintain pulpless yet functional tooth/teeth in the oral cavity through adequate restoration. Such a restoration often requires additional measures along with conventional restorations keeping in mind factors, such as existing carious/noncarious lesion, considerable loss of tooth structure, presence of previous restorations and at times, the endodontic treatment itself. ${ }^{1}$

There are several materials and techniques currently available to restore root canal treated (RCT) tooth/teeth with the traditional restorative practices now being altered based on availability of newer materials and patient preferences. ${ }^{2}$ While there are several guidelines available regarding the best practices in different restorative situations, the option chosen is often influenced by factors, such as personal preference, years of professional

Lecturer

Department of Operative Dentistry, Al-Quds University Jerusalem, Palestine

Corresponding Author: Tarek H Rabi, Lecturer, Department of Operative Dentistry, Al-Quds University, Jerusalem, Palestine Phone: 97252244413, e-mail: tarekrabi@gmail.com experience and geographical region. ${ }^{3}$ While there are several studies evaluating the dentists' attitudes and practices while restoring RCT teeth, there are currently no such studies which have assessed the attitudes of Palestinian dentists. The current study was carried out to understand the attitudes and practices of the dentists in Palestine regarding the restoration of endodontically treated tooth/teeth based on their gender, years of professional experience and type of practice.

\section{MATERIALS AND METHODS}

This study was carried out among Palestinian dentists by means of an online self-administered questionnaire. Three hundred dentists registered with the Palestine Dental Association were randomly selected and the questionnaire was e-mailed to them.

The questionnaire used in this study was adapted from a similar study performed in Greece, with slight modifications. ${ }^{4}$ The questionnaire used in this study was an online form consisting of a total of 18 multiple choice questions. Personal information, such as name of the dentist was not sought to maintain anonymity. While the first three questions focussed on demographic details, such as gender, type of practice and years of experience, rest of them were designed to understand the attitudes related to the need for post in RCT tooth/teeth and its benefits; types of post used, along with techniques and additional procedures followed during post placement; and core build-up preferences (Tables 2 to 4 ). The study received the needed ethical approval from Al-Quds University Research and Ethics Committee under the number 9/REC/18.

Contingency tables were used to evaluate the data obtained and conclusions were drawn through Chisquared distribution test with p-value as supplements. Preferences were also categorized based on gender, type of practice and years of professional experience. All the statistical analyses were performed using the statistical package for the social sciences (SPSS) version 13 statistical software (SPSS Inc, Chicago, IL, USA).

\section{RESULTS}

Three hundred dentists were given the questionnaire, out of which 204 dentists (mean age: $29.62 \pm$ ? years) completed 


\begin{tabular}{|c|c|}
\hline Parameter & $N$ \\
\hline \multicolumn{2}{|l|}{ Gender } \\
\hline Male & $160(78.43 \%)$ \\
\hline Female & $44(21.56 \%)$ \\
\hline \multicolumn{2}{|l|}{ Type of practice } \\
\hline General Dentists & $190(93.17 \%)$ \\
\hline Specialists & $14(6.86 \%)$ \\
\hline \multicolumn{2}{|c|}{ Years of practice (years) } \\
\hline $0-5$ & $91(44.60 \%)$ \\
\hline $6-10$ & $63(30.88 \%)$ \\
\hline $11-15$ & $30(14.70 \%)$ \\
\hline$>15$ & $20(9.80 \%)$ \\
\hline
\end{tabular}

them and returned with $68 \%$ response rate. Majority of the dentists who responded were males (78.4\%). The study population included both general dentists (93.1\%) and specialists $(6.8 \%)$ (Table 1$)$. While a majority of those who responded had a professional experience of less than 6 years $(44.6 \%)$, a substantial percentage of them had an experience of 6 to 10 years (30.8\%).

\section{NEED FOR POST AND ITS BENEFITS (TABLE 2)}

The need for post and its benefits were evaluated in the questions 4 to 6 (Table 2). Both male and female dentists widely believed that every endodontically treated tooth does not require a post (74.3 and $93.2 \%$, respectively). The percentage of doctors who believed that every RCT tooth does not require a post was evenly distributed through years of experience. Further, the type of practice did not have an influence on the requirement of a post (both, general dentists and specialists believed that every endodontically treated tooth did not require a post).
Male dentists widely believed that placing a post reinforces an endodontically treated tooth $(60.6 \%)$, while female dentists believed otherwise (61.4\%). In terms of professional experience, doctors with more experience (more than 6 years) widely agreed (average score 54.9\%) that placement of a post does not reinforce the RCT tooth. On the contrary, dentists with an experience less than 5 years strongly supported the notion that a post would reinforce the RCT tooth (65.9\%). Type of practice did not have an impact on the opinion about this belief.

Majority of the dentists (males and female) agreed that they consider placing a post in a RCT tooth being used as an abutment in 30 to $50 \%$ of the cases only. However, about $11 \%$ dentists agreed that they place a post in all the endodontically treated teeth being considered as an abutment.

In terms of posts being placed in RCT tooth considered to be used as an abutment, most female and male dentists (50 and $67.5 \%$, respectively) reported that RCT tooth/ teeth was used as abutments in 30 to $50 \%$ of the cases. This was more common among those with 6 to 10 years of experience $(76.2 \%)$ but did not vary with the type of practice.

\section{Post Techniques and Additional Procedures (Table 3)}

The findings related to the attitudes and techniques followed during post placement and material preferences along with the importance of ferrule have been elaborated in Table 3.

All the surveyed dentists were generally in favor of the belief that a ferrule increases the resistance of endodontically treated tooth. When using a post, preference

Table 2: Attitudes of dentists toward the use of post in RCT toot

\begin{tabular}{|c|c|c|c|c|c|c|c|c|c|c|c|c|c|c|c|}
\hline \multirow[b]{3}{*}{ Variables } & & \multicolumn{4}{|c|}{$\begin{array}{l}\text { Q4. Do you believe that every } \\
\text { RCT tooth requires a post? }\end{array}$} & \multicolumn{4}{|c|}{$\begin{array}{l}\text { Q5. Do you believe that the } \\
\text { placement of a post reinforces } \\
\text { an RCT tooth and reduces the } \\
\text { fracture probability? }\end{array}$} & \multicolumn{6}{|c|}{$\begin{array}{l}\text { Q6. In what percentage of RCT teeth used as } \\
\text { abutments of fixed partial dentures do you place } \\
\text { a post? }\end{array}$} \\
\hline & & \multicolumn{2}{|r|}{ No } & \multicolumn{2}{|r|}{ Yes } & \multicolumn{2}{|r|}{ No } & \multicolumn{2}{|c|}{ Yes } & \multicolumn{2}{|c|}{$30-50$} & \multicolumn{2}{|l|}{$50-70$} & \multicolumn{2}{|r|}{100} \\
\hline & & Count & $\begin{array}{l}\text { Row N } \\
\text { (\%) }\end{array}$ & Count & $\begin{array}{l}\text { Row N } \\
t(\%)\end{array}$ & Count & $\begin{array}{l}\text { Row N } \\
\text { (\%) }\end{array}$ & Count & $\begin{array}{l}\text { Row N } \\
(\%)\end{array}$ & Count & $\begin{array}{l}\text { Row N } \\
\text { (\%) }\end{array}$ & Count & $\begin{array}{l}\text { Row N } \\
\text { (\%) }\end{array}$ & Count & $\begin{array}{l}\text { Row N } \\
t(\%)\end{array}$ \\
\hline Gender & Female & 41 & 93.18 & 3 & 6.82 & 27 & 61.36 & 17 & 38.64 & 22 & 50.00 & 17 & 38.64 & 5 & 11.36 \\
\hline \multirow{5}{*}{$\begin{array}{l}\text { Years of } \\
\text { experi- } \\
\text { ence }\end{array}$} & Male & 119 & 74.38 & 41 & 25.63 & 63 & 39.38 & 97 & 60.63 & 108 & 67.50 & 35 & 21.88 & 17 & 10.63 \\
\hline & $0-5$ & 68 & 74.73 & 23 & 25.27 & 31 & 34.07 & 60 & 65.93 & 60 & 65.93 & 18 & 19.78 & 13 & 14.29 \\
\hline & $6-10$ & 55 & 87.30 & 8 & 12.70 & 30 & 47.62 & 33 & 52.38 & 48 & 76.19 & 13 & 20.63 & 2 & 3.17 \\
\hline & $11-15$ & 23 & 79.31 & 6 & 20.69 & 16 & 55.17 & 13 & 44.83 & 14 & 48.28 & 12 & 41.38 & 3 & 10.34 \\
\hline & $>15$ & 14 & 66.67 & 7 & 33.33 & 13 & 61.90 & 8 & 38.10 & 8 & 38.10 & 9 & 42.86 & 4 & 19.05 \\
\hline \multirow[t]{2}{*}{$\begin{array}{l}\text { Type of } \\
\text { practice }\end{array}$} & $\begin{array}{l}\text { General } \\
\text { dentist }\end{array}$ & 146 & 76.84 & 44 & 23.16 & 82 & 43.16 & 108 & 56.84 & 118 & 62.11 & 50 & 26.32 & 22 & 11.58 \\
\hline & $\begin{array}{l}\text { Speci- } \\
\text { alist }\end{array}$ & 14 & 100.00 & 0 & 0.00 & 8 & 57.14 & 6 & 42.86 & 12 & 85.71 & 2 & 14.29 & 0 & 0.00 \\
\hline
\end{tabular}


was given to screw type prefabricated posts and those made of nonprecious alloy. Most of the dentists attempt to place a post that was equal to $1 / 3$ of remaining root length. Gender, type of practice and years of experience did not seem to have an influence on the choices made.

\section{Core Build-up Preferences (Table 4)}

Direct pattern technique was the most favored type of impression technique during core build-up among male dentists (41.3\%) while female dentists were indifferent to the impression technique followed/preferred (50\% chose the option 'both' for the preference of core build-up technique). Specialists were indifferent to the technique (71.4\% chose the option 'both') which was correlated to the years of experience (over 15 years of experience; $42.9 \%$ chose the option 'both') while dentists with lesser experience ( $<5$ years) widely preferred direct pattern technique $(45.1 \%)$.

Gender and years of experience, however did not have a major influence on the type of post and core material used for the restoration of endodonticaly treated anterior and posterior teeth. The most preferred post and core material for posterior teeth (based on average percentage of dentists choosing this option) was prefabricated

Table 3: Attitudes regarding placement of ferrule and post preferences

\begin{tabular}{|c|c|c|c|c|c|c|c|c|c|c|c|c|}
\hline & \multicolumn{2}{|c|}{$\begin{array}{l}\text { Q7. Do you } \\
\text { believe that a } \\
\text { ferrule increases } \\
\text { the fracture } \\
\text { resis- } \\
\text { tance of RCT } \\
\text { teeth when atta- } \\
\text { ched to the post? }\end{array}$} & \multicolumn{4}{|c|}{$\begin{array}{l}\text { Q8. If you use prefabricated post, } \\
\text { which type of prefabricated post do } \\
\text { you use most frequently? }\end{array}$} & \multicolumn{6}{|c|}{$\begin{array}{l}\text { Q9. If you use cast posts and cores, which material alloy do } \\
\text { you prefer most frequently? }\end{array}$} \\
\hline & No (\%) & Yes (\%) & $\begin{array}{l}\text { Fiber } \\
\text { post } \\
(\%)\end{array}$ & $\begin{array}{l}\text { Parallel } \\
\text { sided } \\
(\%)\end{array}$ & $\begin{array}{l}\text { Screw } \\
\text { type } \\
(\%)\end{array}$ & $\begin{array}{l}\text { Tapered } \\
(\%)\end{array}$ & $\begin{array}{l}\text { No } \\
\text { data } \\
(\%)\end{array}$ & $\begin{array}{l}\text { All } \\
\text { ceramic } \\
(\%)\end{array}$ & $\begin{array}{l}\text { Gold } \\
\text { cast } \\
(\%)\end{array}$ & $\begin{array}{l}\text { Nonpre- } \\
\text { cious } \\
\text { Alloy } \\
(\%)\end{array}$ & $\begin{array}{l}\text { Palladium } \\
\text { silver alloy } \\
(\%)\end{array}$ & $\begin{array}{l}\text { Titanium } \\
(\%)\end{array}$ \\
\hline Female & 18.2 & 81.8 & 9.1 & 2.3 & 63.6 & 25.0 & 9.1 & 4.5 & 6.8 & 50.0 & 11.4 & 18.2 \\
\hline Male & 33.8 & 66.3 & 7.5 & 11.9 & 68.8 & 11.3 & 14.4 & 4.4 & 3.8 & 63.1 & 7.5 & 6.9 \\
\hline $\begin{array}{l}\text { General } \\
\text { dentist }\end{array}$ & 32.1 & 67.9 & 7.9 & 7.9 & 69.5 & 14.2 & 13.7 & 4.7 & 4.7 & 58.9 & 8.4 & 9.5 \\
\hline Specialist & 7.1 & 92.9 & 7.1 & 35.7 & 42.9 & 14.3 & 7.1 & 0.0 & 0.0 & 78.6 & 7.1 & 7.1 \\
\hline $0-5$ & 24.2 & 75.8 & 5.5 & 7.7 & 67.0 & 18.7 & 22.0 & 5.5 & 3.3 & 40.7 & 13.2 & 15.4 \\
\hline $6-10$ & 36.5 & 63.5 & 6.3 & 11.1 & 73.0 & 9.5 & 4.8 & 1.6 & 1.6 & 84.1 & 4.8 & 3.2 \\
\hline $11-15$ & 17.2 & 82.8 & 3.4 & 17.2 & 72.4 & 6.9 & 3.4 & 3.4 & 3.4 & 82.8 & 6.9 & 0.0 \\
\hline$>15$ & 57.1 & 42.9 & 28.6 & 4.8 & 47.6 & 19.0 & 14.3 & 9.5 & 19.0 & 42.9 & 0.0 & 14.3 \\
\hline
\end{tabular}

Table 4: Attitudes regarding core build-up preferences

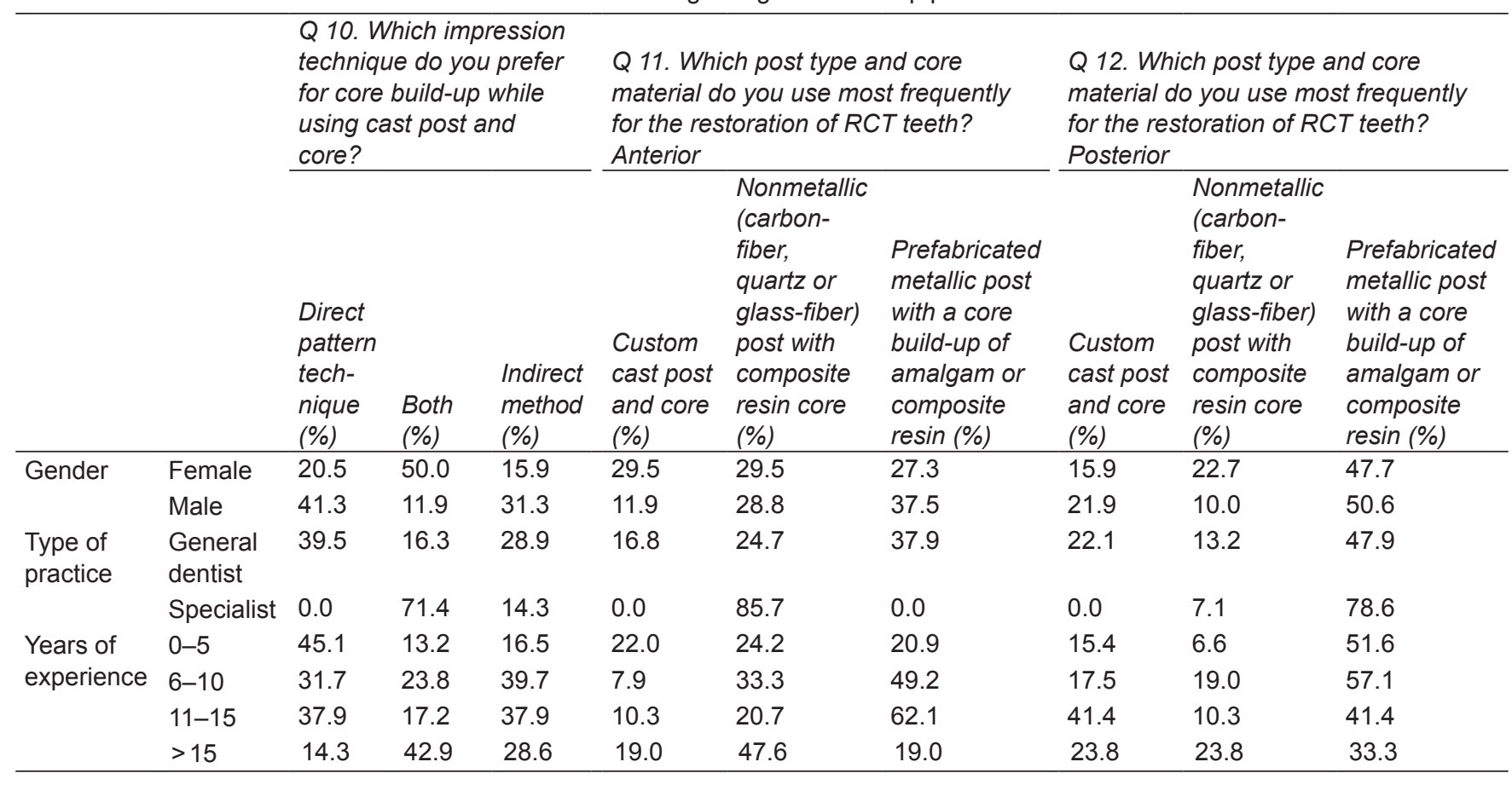


metallic post with a core build-up of amalgam or composite resin (51.0\%); while in case of anterior teeth preference was given to nonmetallic (carbon-fiber, quartz or glass-fiber) post with composite resin core $(36.8 \%)$. Among specialists, nonmetallic posts were preferred for anterior teeth $(85.7 \%)$, while prefabricated metallic posts were most preferred for posterior teeth (78.6\%).

\section{DISCUSSION}

Biomechanical properties of the tooth/teeth following endodontic therapy play a vital role in the decision about methods followed during restoration of RCT tooth. Loss of hard-tissues because of carious/noncarious lesions and tooth preparation (including access cavity preparation) would have already compromised the strength of the tooth, increasing their risk of fracture. Endodontic procedures, including cleaning and shaping of the canals can further accentuate this risk. ${ }^{6}$ Apart from good endodontic treatment, successful restoration of a tooth with pulpal involvement is also dependent on prosthetic reconstruction, following endodontic therapy. ${ }^{7}$

The study revealed varying attitudes and beliefs of Palestinian dentists regarding the restoration of a tooth following endodontic therapy. The overall response was good considering the number of dentists who were enthusiastic enough to share their thoughts about these aspects. Although, general dentists comprised majority of the study population. This study helps us to understand the attitudes of both general dentists and specialists, and to know whether there is a wide variation in their beliefs regarding these practices. The discussion has been segregated under different headings to evaluate whether the options chosen by Palestinian dentists match the guidelines (if any) or commonly followed practices in other parts of the world.

\section{Need for Posts and its Benefits}

The primary purpose of a post is to retain a core in a tooth with extensive loss of coronal tooth structure. ${ }^{8,9}$

However, preparation of a post space adds a certain degree of risk to a restorative procedure. Procedural accidents may occur during post space preparation. The placement of posts also may increase the chances of root fracture ${ }^{10}$ and treatment failure, ${ }^{11}$ especially if an oversized post channel is prepared. It must be used when there are no more options available. The need of the post is different in anterior and posterior teeth.

If an endodontically treated anterior tooth is to receive a crown, a post often is indicated. Anterior teeth must resist lateral and shearing types of forces, and the pulp chambers are too small to provide adequate retention and resistance without a post. ${ }^{12}$
Molars must resist primarily vertical forces. In those molars that do require a post, the post should be placed in the largest, straightest canal, which is the palatal canal in the maxillary molars and a distal canal in the mandibular molars. $^{12}$

Basically, posts help provide retention to the core material and are often used in the restoration of endodontically treated tooth/teeth. While placement of a post is not required if sufficient anatomical structure which can retain the core is present, it may be necessary in cases where there is extensive loss of coronal structure. ${ }^{13}$ Thus, posts become a supportive system for extensively damaged teeth.

The placement of a post in RCT teeth for 'reinforcement' has been a matter of debate for long. While some support the placement of post as a mode of strengthening or reinforcing an endodontically treated tooth, others contradict this suggesting that the risk of fracture increases as the tooth is prepared to receive a post.

Previously, the use of posts was thought to reinforce the teeth. However, clinical studies have failed to prove such a benefit. ${ }^{14}$ In general, posts are placed in endodontically treated teeth to help retain the core, which in turn improves crown retention. ${ }^{15}$ However, this primary purpose of the posts remains unrecognized to a significant extent. Restorative dentists seem to widely believe that all endodontically treated teeth are weakened and hence require aggressive reinforcement measures involving placement of a post followed by a crown. ${ }^{16}$

In a study in Sweden involving general dental practitioners and board certified prosthodontists, about $29 \%$ of the general practitioners and $17 \%$ of prosthodontists considered the use of post for reinforcing the RCT tooth. ${ }^{17}$ A majority of the general practitioners in Germany were also of the belief that post reinforces endodontically treated teeth. ${ }^{18}$

In the current study, male dentists widely believed that placing a post reinforces an endodontically treated tooth. It was also noted that dentists with an experience less than 5 years strongly supported this notion. However, female dentists and dentists with more experience (more than 6 years) replied otherwise. Additionally, the type of practice did not seem to have an influence on this belief as almost equal percentage of specialists and general practitioners supported or refuted this claim.

Majority of dentists (males and females) in the current study also agreed that every RCT tooth does not require a post. This is supported by the findings based on in vivo and in vitro studies which reported that the strength of an endodontically treated tooth is directly related to the remaining tooth structure, but such a tooth is not strengthened with the use of a post. Hence, there may not be a need to place a post in all endodontically 
treated teeth. A similar finding was reported in the Swedish study where only a few dentists used post 'always' or 'most of the times'. Accordingly, the choice to place a post in an endodontically treated tooth should be individualized, weighing the pros and cons before opting to do so.

As the placement of a post does not seem to reinforce the tooth that has undergone endodontic treatment, its placement in tooth/teeth being considered as abutments also seems questionable. Peroz et al however suggested the use of posts in endodontically treated teeth being used as abutments for removable partial dentures. In the current study, majority of the dentists (average 58.7\%) placed a post in only 30 to $50 \%$ of the instances where the tooth was being used as an abutment. This was slightly higher than noted in a similar study involving Greek dentists where about $46 \%$ of the dentists reported this practice. On the other hand, majority of dentists in the Swedish study used posts when restoring RCT teeth with crowns or fixed partial dentures.

\section{Post Techniques and Additional Procedures}

\section{Use of Ferrule}

The ferrule basically provides bracing and casing action to protect the integrity of the root. Of paramount importance to the longevity of the restored endodontically treated tooth is the presence of adequate height $(1.5-2 \mathrm{~mm})$ of sound tooth structure, or ferrule, between the core and the crown margin. ${ }^{19}$

A minimal $1 \mathrm{~mm}$ ferrule is considered necessary to stabilize the endodontically treated tooth. The presence of a ferrule increases the fracture resistance of an endodontically treated tooth and reduces the risk of vertical fracture by one-third. ${ }^{20}$ Accordingly, majority of the surveyed dentists (average $71.7 \%$ ) in the current study were of the belief that a ferrule increases the fracture resistance of endodontically treated tooth. This percentage was higher than that noted in other similar studies in Sweden $(53.0 \%)^{21}$ and in the United States $(56.0 \%)^{22}$

When a crown is placed on a tooth with optimal ferrule, the crown and root function as one integrated unit and occlusal forces are transmitted in normal physiological fashion to the periodontium. Where inadequate ferrule exists, occlusal stresses are transferred directly to the core and/or post with high likelihood of tooth, root or post fracture or post dislodgement.

\section{Post Type}

Multiple types of post materials are currently available and are broadly categorized as metal alloy posts and nonmetal alloy posts. The latter type, which include custom fabricated resin composite and ceramic post cores, and prefabricated ceramic and fiber-reinforced polymer posts, are being preferred widely in the recent times. Some of the advantages reported with the use of such posts include, closer match with the modulus of elasticity of dentin, fewer root fracture failures and possible strengthening of the tooth. ${ }^{23}$

The choice of post is influenced by a number of factors including their benefits in specific situations. In general, while custom made post and core facilitate close adaptation to the post space, prefabricated posts have the advantage of being able to be placed in a single sitting. ${ }^{24}$ In the current survey, preference was given to screw type prefabricated posts and those made of nonprecious alloy. Similarly, screw type was the most popularly preferred prefabricated posts (47\%) in the German study mentioned earlier. ${ }^{18}$ Another study among Greek dentists revealed similar results wherein screw type prefabricated metallic post was mostly preferred (46\%) and nonprecious alloy was the material chosen more frequently (38.7\%). ${ }^{5}$

While placing a post in anterior or posterior teeth, the shape of the canal would dictate the type of post core system to be used. In case of anterior teeth with small circular canals, prefabricated post with resin composite core is considered beneficial while customized post core would be apt for teeth with elliptical or flared canals. Similarly, in case of posterior teeth with circular canals (as seen in cross-section), prefabricated posts with resin composite or amalgam cores are considered acceptable. If the canals are extremely tapered, then custom cast metal posts and cores are to be preferred. ${ }^{25}$

Gender and years of experience, did not have a major influence on the type of post and core material used for the restoration of endodontically treated anterior and posterior teeth in the current study. The most preferred post and core material for anterior teeth was nonmetallic (carbon-fiber, quartz or glass-fiber) post with composite resin core while prefabricated metallic post with a core build-up of amalgam or composite resin was preferred for posterior teeth. This finding was similar to that noted in a UK based study. ${ }^{23}$ Among specialists, nonmetallic posts were preferred for anterior teeth (85.7\%), while prefabricated metallic posts were most preferred for posterior teeth $(78.6 \%)$.

\section{Post Length}

It is logical to believe that longer the post in the root canal, the higher is its retention; but, the risk of fracture and perforation also increases substantially. ${ }^{25}$ According to certain acceptable guidelines related to the post length, the post length should be equal to the clinical crown length or should be equal to one-half to two-thirds of the length of the remaining root or should extend to one-half the length of the root that is supported by bone.? 
The findings of the current survey were in norms with these guidelines wherein most of the dentists $(36.6 \%)$ mentioned that they attempt to place a post that was equal to $1 / 3$ of remaining root length. In the Greek study, $58 \%$ of the respondents made their posts two-thirds of the root's length. ${ }^{5}$

\section{Core Build-up Preferences}

Core build-up is considered necessary in teeth with reduced residual tooth substance as it augments retention and resistance of the remaining tooth structure. ${ }^{26}$ The fabrication methods followed and the type of luting cement used is reported to have a significant influence on the retention of posts. ${ }^{27}$ A study evaluating direct and indirect cast dowel core crowns reported better retention with dowel cores made by the indirect method. Easy manipulation during the fabrication period and good marginal adaptation were the benefits reported with the indirect method..$^{28}$ Similar outcome was reported in another recent study which noted better fit and higher accuracy with indirect method of fabricating cast post and core. ${ }^{29}$

In the current survey however, male dentists and those with lesser experience ( $<5$ years) favored direct pattern impression technique for post core build-up. On the other hand, while female dentists were indifferent toward the technique, dentists with $>15$ years of experience preferred the indirect method for fabricating cast post and core.

\section{CONCLUSION}

The practices and attitudes of Palestinian dentists related to the restoration of the teeth following endodontic therapy were mostly in line with the practices followed elsewhere. Nevertheless, there were certain variations in these beliefs when gender, type and years of experience were considered. From the above results it can be concluded that female dentists and those with more experience ( $>6$ years) widely believed that post does not reinforce the endodontically treated teeth. Majority of the dentists (irrespective of gender, type of practice and years of experience) believed that post was not required in all endodontically treated teeth. Most of them (irrespective of gender, type of practice and years of experience) believed that ferrule increases fracture resistance of the endodontically treated teeth. It can also be inferred that prefabricated posts were mostly preferred and the length of the post was to be $1 / 3$ of the remaining root length. Dentists with $>15$ years of experience are still preferring indirect method for the fabrication of post and core. Taking steps to inform dentists about recent evidences regarding these practices would help in bringing uniformity in such procedures, which would in turn improve the outcomes of these procedures.

\section{REFERENCES}

1. Dimitriu B, Vârlan C, Suciu I, Vârlan V, Bodnar D. Current considerations concerning endodontically treated teeth: alteration of hard dental tissues and biomechanical properties following endodontic therapy. J Med Life 2009;2(1):60-65.

2. Bateman G, Ricketts DNJ, Saunders WP. Fiber-based post systems: a review. Br Dent J 2003;195(37):43-48.

3. Bader JD, Shugars DA. Understanding dentists' restorative treatment decisions. Public Health Dent J 1992;52:102-110.

4. Scurria MS, Shugars DA, Hayden WJ, Felton DA. General dentists' patterns of restoring endodontically treated teeth. JADA 1995;126:775-779.

5. Tortopidis D, Papa P, Menexes G, Koidis P. Attitudes of dentists regarding the restoration of root canal treated teeth: a survey in Greece. International Dental Journal 2010;60:336-342.

6. Trope M, Ray HL. Resistance to fracture of endodontically treated roots. Oral Surg Oral Med Oral Pathol J 1992;73:99-102.

7. Cheung W. A review of the management of endodontically treated teeth. Post, core and the final restoration. Am Dent Assoc J 2005;136(5):611-619.

8. Robbins JW. Guidelines for the restoration of endodontically treated teeth. J Am Dent Assoc 1990;120:558-566.

9. Goodacre CJ, Spolnik KJ. The prosthodontic management of end-odontically treated teeth: a literature review. Part I. Success and failure data, treatment concepts. J Prosthod 1994; 3:243-250.

10. Heydecke G, Butz F, Strub JR. Fracture strength and survival rate of endodontically treated maxillary incisors with approximal cavities after restoration with different post and core systems: an in-vitro study. J Dent 2001;29:427-433.

11. Sorensen JA, Martinoff JT. Endodontically treated teeth as abutments. J Prosthet Dent 1985;53:631-636.

12. Richard S, James, Robbins W. Post placement and restoration of endodontically treated teeth: a literature review. Journal of Endodontics 2004;30(5):290-291.

13. Peroz I, Blankenstein F, Lange KP, Naumann M. Restoring endodontically treated teeth with posts and cores-a review. Quintessence Int 2005;36(9):737-746.

14. Baba NZ, Goodacre CJ. Key principles that enhance success when restoring endodontically treated teeth. Roots 2011;7(2):30-35.

15. Schwartz RS, Robbins JW. Post placement and restoration of endodontically treated teeth: a literature review. Endod J 2004;30(5):289-301.

16. Smith CT, Schuman N. Restoration of endodontically treated teeth: a guide for the restorative dentist. Quintessence Int 1997;28(7):457-462.

17. Eckerbom M, Magnusson T. Restoring endodontically treated teeth: a survey of current opinions among board certified prosthodontists and general dental practitioners in Sweden. Int J Prosthodont, 2001;14(3):245-249.

18. Naumann M, Kiessling S, Seemann R. Treatment concepts for restoration of endodontically treated teeth: a nationwide survey of dentists in Germany. Prosthet Dent J 2006;96(5): 332-338.

19. Restoration of endodontically treated tooth. Available from: www.rcdso.org/save.aspx?id=68f72e1f-1fd1-42ba-bf6b21c884da92e0. 
20. Slutzky-Goldberg I, Slutzky H, Gorfil C, Smidt A. Restoration of endodontically treated teeth review and treatment recommendations. Int J Dent 2009;2009:150251.

21. Slaus G, Bottenberg P. A survey of endodontic practice amongst Flemish dentists. Int Endod J 2002;35(9):759-767.

22. Tang $\mathrm{W}, \mathrm{Wu} \mathrm{Y}$, Smales RJ. Identifying and reducing risks for potential fractures in endodontically treated teeth. Endod J 2010;36(4):609-617.

23. Vârlan C, Dimitriu B, Vârlan V, Bodnar D, Suciu I. Current opinions concerning the restoration of endodontically treated teeth: basic principles. Med Life J 2009;2(2):165-172.

24. Seow LL, Toh CG, Wilson NH. A survey of current practices among general dental practitioners in Manchester in 2002. Prim Dent Care, 2002;10(3):87-92.
25. Leary JM, Aquilino SA, Svare CW. An evaluation of post length within the elastic limits of dentin. J Prosthet Dent 1987 Mar;57(3):277-281.

26. Christensen GJ. When to use fillers, build-ups or posts and cores. JADA 1996;127:1397-1398.

27. Ma HM, Li ZC, Li H, Chen X. The effect of different fabrication methods and luting cements on post retention. Hua Xi Kou Qiang Yi Xue Za Zhi J 2004;22(2):152-154.

28. Li C, Feng YZ. Clinical evaluation of extensively damaged pulpless anterior teeth restored with direct and indirect cast dowel core crowns. Zhong Nan Da Xue Xue Bao Yi Xue Ban 2004;29(4):475-477.

29. Pitigoi-Aron G, Streacker AB, Schulze KA, Geissberger M. Accuracy of cast posts and cores using a new investigative method. Gen Dent J 2012;60(3):153-157. 